\title{
An Efficient Electrochemical Sensor Based on Zirconium Molybdate Decorated Reduced Graphene Oxide for the Detection of Hydroquinone
}

\author{
Nandini Nataraj ${ }^{1}$, Tse-Wei Chen ${ }^{2}$, Shen-Ming Chen ${ }^{1, *}$, Syang-Peng Rwei ${ }^{3,4}$ \\ ${ }^{1}$ Department of Chemical Engineering and Biotechnology, National Taipei University of Technology, \\ No.1, Section 3, Chung-Hsiao East Road, Taipei 106, Taiwan. \\ ${ }^{2}$ Department of Materials, Imperial College London, London, SW7 2AZ, United Kingdom \\ ${ }^{3}$ Research and Development Center for Smart Textile Technology, National Taipei University of \\ Technology, Taiwan \\ ${ }^{4}$ Institute of Organic and Polymeric Materials, National Taipei University of Technology, Taiwan \\ *E-mail: smchen78@ms15.hinet.net, smchen1957@ gmail.com
}

doi: $10.20964 / 2020.08 .42$

Received: 6 May 2020 / Accepted: 22 June 2020 / Published: 10 July 2020

\begin{abstract}
The present work concentrates over the electrochemical sensing of hydroquinone (HQ) with modified Zirconium Molybdate Decorated Reduced Graphene Oxide $\left(\mathrm{Zr}\left(\mathrm{MoO}_{4}\right)_{2} @ \mathrm{rGO} / \mathrm{GCE}\right) . \mathrm{Zr}\left(\mathrm{MoO}_{4}\right)_{2} @ \mathrm{rGO}$ was synthesized by a facile hydrothermal method. Followed with the characterization of the as prepared material was examined with XRD, FTIR and FESEM along with their application was employed with cyclic voltammetry technique. Results obtained from XRD and FTIR clearly demonstrated that $\mathrm{Zr}\left(\mathrm{MoO}_{4}\right)_{2} @ \mathrm{rGO}$ have been formed with good crystallinity and morphology. Differential pulsed voltammetry studies further declared the limit of detection and Linear range as $0.015 \mu \mathrm{M}$ and $0.01-250$ $\mu \mathrm{M}$ with the sensitivity about $0.02042 \mu \mathrm{A} \mu \mathrm{M}^{-1} \mathrm{~cm}^{-2}$. River water, waste water and tap water were implied for the real time applicability of the fabricated sensor. Interference studies as performed revealed that no other similar compounds have been interfered with HQ and along with this the repeatability, reproducibility and stability performances explains the excellent behavior of the as prepared sensors efficiency in repeated cycles and in numerous electrodes. Thus, the fabricated sensor could be a simple, effective and selective sensor for detection of HQ.
\end{abstract}

Keywords: Hydrothermal method; zirconium molybdate; reduced graphene oxide; hydroquinone (HQ); electrochemical detection. 
(C) 2020 The Authors. Published by ESG (www.electrochemsci.org). This article is an open access article distributed under the terms and conditions of the Creative Commons Attribution license (http://creativecommons.org/licenses/by/4.0/). 